\title{
Novel molecular targets in the search for anti-inflammatory agents
}

\author{
M. Lienhard Schmitz* \& Susanne Bacher \\ Department of Chemistry and Biochemistry, University of Bern, Freiestr. 3, CH3012, Bern, Switzerland; *Author \\ for correspondence (Tel: +41-31631-4315; Fax:+41-31631-4887; E-mail: Lienhard.Schmitz@ibc.unibe.ch)
}

Key words: inflammation, interleukin, JNK, NF- $\kappa \mathrm{B}$, p38, signal transduction, $\mathrm{TNF} \alpha$

\begin{abstract}
In the chronic state of inflammatory diseases, cellular signaling networks aimed at combating invading pathogens are often constitutively active and transmit their signals even in the absence of inflammatory agents. Thus, many anti-inflammatory drugs interfere with these dys- and hyperactivated cellular signaling networks or transcription factors. As many signaling molecules fulfill important and essential functions in normal cell physiology, their systemic and long-term inhibition may lead to severe side effects including an impaired immune response. To circumvent these pitfalls, two possibilities are proposed and discussed here: (I) Since many inflammatory diseases such as rheumatoid arthritis or inflammatory bowel disease are restricted to certain cell types or tissues, a new generation of anti-inflammatory drugs would target enzymes that are only operational in these affected tissues. (II) As some signaling pathways affect solely a small subset of inflammatory target genes, their inhibition bears the potential of limiting potential side effects.

Abbreviations: COX-2 - cyclooxygenase-2; TNF $\alpha$ - tumor necrosis factor $\alpha$; IL - interleukin; LPS lipopolysaccharide; MAPKs - mitogen-activated protein kinases; ERK - extracellular-signal-regulated kinase; JNK - c-Jun N-terminal kinase; MAPKKs - MAPK kinases; MAPKKKs - MAPK kinase kinases; MMP - matrix metalloproteinase; TAB1 - transforming growth factor- $\beta$-activated protein kinase 1 (TAK1)-binding protein 1; NSAIDs - non-steroidal anti-inflammatory drugs; TCR $-\mathrm{T}$ cell receptor; C/EBP - CCAAA/enhancer-binding protein; LT $\beta$ - lymphotoxin $\beta$.
\end{abstract}

\section{Inflammation}

Inflammation can be caused by a variety of stimuli including physical damage, UV irradiation, immune reactions and microbial invasion. The classical key features of inflammation are redness, warmth, swelling and pain. Besides systemic features such as fever and the acute phase response, inflammation is a primarily local event. The inflammatory process attracts leukocytes from the intravascular compartment to the site of damage, which is mediated by cytokines, chemokines, cell surface proteins and further mechanisms (Johnston and Butcher, 2002; Marra, 2002). In addition, the inflammatory process leads to an induced expression and enzymatic activity of enzymes such as cyclooxygenase-2 (COX-2) and NO synthase which produce inflammatory mediators such as eicosanoids and NO. These mediators serve to augment the local blood flow. Invading microorganisms are engulfed by phagocytic cells including neutrophils and macrophages in order to maintain the infection in a restricted space. During phagocytosis, an oxidative burst helps to destroy the invading pathogens (Winrow et al., 1993; Marra, 2002).

Phagocytic cells also remove tissue debris and dead cells. Damage is repaired by proliferation of fibroblasts and vascular capillary endothelial cells to form granulation tissue and eventually a fibrous scar. Inflammation occurs early after damage and 
even when only low concentrations of pathogens are present. Therefore, proinflammatory cytokines such as tumor necrosis factor (TNF) $\alpha$ and interleukin (IL) 1, IL-17 and IL-18 serve to trigger and rapidly amplify the inflammatory response in order to limit spreading of the infection. Upon removal of the causing agent the inflammation normally subsides. This process is actively mediated by regulatory factors such as anti-inflammatory cytokines (e.g. IL-10, IL-13) and glucocorticoids (Kubo et al., 2003). While inflammation is a necessary and effective part of the normal innate immune response, in some situations the inflammatory process continues even in the absence of inflammatory agents. Inappropriate activation of the immune system frequently occurs in chronic inflammatory diseases, which are characterized by overproduction of immune cells, tissue-destructive enzymes and inflammatory cytokines. These cells and proteins attack and destroy healthy tissue, thus causing various diseases including rheumatoid arthritis, asthma, inflammatory bowel disease, and psoriasis (Kumar et al., 2001). As a cautionary note it should be stated that these chronic inflammatory diseases are not only caused by a single common event but are rather caused by several, disease-specific changes. Intriguingly, chronic inflammatory diseases are found frequently associated either with (I) constitutively active proinflammatory signaling pathways such as NF- $\kappa \mathrm{B}$ or (II) dysregulated anti-inflammatory signaling.

\section{Receptor-mediated signaling pathways in the inflammatory process}

Early proinflammatory signaling is typically mediated by lipopolysaccharide (LPS) receptors which directly recognize products from the invading pathogen. Later on, further receptors including those for IL-1 and TNF $\alpha$ mediate the inflammatory response. The signaling pathways triggered by the IL-1 and TNF receptors are extensively studied and excellently reviewed elsewhere (Chen and Goeddel, 2002; Dunne and O'Neill, 2003). Briefly, stimulation of these receptors by ligand binding induces conformational changes which attract further proteins including adaptors lacking enzymatic activities and protein kinases, which phosphorylate their substrate proteins. These early events funnel into several signaling pathways such as the activation of NF- $\kappa \mathrm{B}$ (see article by $\mathrm{M}$. Heinrich in this issue) and the mitogen-activated protein kinases (MAPKs) belonging to the ERK (extracellular-signal-regulated kinase), JNK (c-Jun N-terminal kinase) and p38 families. While the ERK kinases are at the heart of signaling pathways governing proliferation and differentiation, JNKs and p38 kinases are important mediators of inflammation and related processes such as cell death (Kracht and Saklatvala, 2002; Kumar et al., 2003; Manning and Davis, 2003).

The MAPKs and their targets phosphorylate and thus activate a variety of transcription factors including NF- $\kappa \mathrm{B}, \mathrm{AP}-1, \mathrm{C} / \mathrm{EBP}$ and ETS which contribute to the induced expression of a battery of mediators of the inflammatory response including adhesion proteins, cytokines, chemokines, proteins involved in antigen presentation, stress response genes and acute phase proteins. MAPKs are activated by dual phosphorylation at conserved threonine and tyrosine residues by MAPK kinases (MAPKKs) which in turn are substrates for MAPK kinase kinases (MAPKKKs) (Dong et al., 2002). While the direct activators for each MAPK are relatively well defined, the highly complex and interconnected signaling pathways triggering activation of MAPKKs are less completely understood.

The JNK family consists of $10 \mathrm{JNK}$ isoforms that are created by alternative splicing of messenger RNA transcripts derived from three genes: JNK1, JNK2 and JNK3. Mouse knockout studies revealed an essential contribution of JNK to $\mathrm{TNF} \alpha$-stimulated phosphorylation of c-Jun, a subunit of the AP-1 transcription factor complex (Ventura et al., 2003). The JNK pathway contributes to the expression of many proinflammatory genes, including those encoding TNF, IL-2, E-selectin and the matrix metalloproteinase (MMP) collagenase-1 (Holzberg et al., 2003). In addition, the JNK pathway regulates TNF production in bacterial lipopolysaccharide-stimulated macrophages, and in mast cells stimulated through the FceRI receptor (Ishizuka et al., 1998).

The p38 family of MAP kinases includes serine-threonine kinases, which are mammalian homologues of the HOG-1 MAP kinase in Saccharomyces cereviciae. The four known p38 isoforms share significant amino acid homology with each other and include $\mathrm{p} 38 \alpha, \mathrm{p} 38 \beta, \mathrm{p} 38 \gamma$ and p38 (Johnson and Lapadat, 2002). p38 MAPK is 
activated by dual phosphorylation of threonine 180 and tyrosine 182 by MKK6 and probably also MKK3. In addition, a MAPKK-independent mechanism of p38 MAPK activation involving TAB1 (transforming growth factor- $\beta$-activated protein kinase 1 (TAK1)-binding protein 1) has been described. It has been shown that its serine kinase activity mediates phosphorylation of transcription factors and regulation of downstream gene transcription. These events mediate induced cytokine production, platelet aggregation, regulation of hepatocyte growth and contribute to organization of the actin cytoskeleton. Furthermore, p38 exhibits regulatory effects in the induction of apoptosis (Pedersen et al., 2002) and cell differentiation (Alsayed et al., 2001) dependent on the cell context.

\section{Signaling pathways as frequent targets for commonly used anti-inflammatory drugs}

Although known and used for decades, it was discovered much later that many anti-inflammatory agents interfere with key signaling pathways. For example, glucocorticoids are still frequently employed for the treatment of chronic inflammations. Besides their ability to induce/repress gene expression via binding to the glucocorticoid receptor, a considerable extent of their efficacy may be due to their ability to interfere with other transcription factors such as AP-1 and NF- $\kappa$ B (De Bosscher et al., 2003) and to inhibit JNK signaling (Caelles et al., 1997). Another example is cyclosporin A (CsA), which forms a complex with cyclophilin to inhibit the phosphatase activity of calcineurin. As the enzymatic activity of calcineurin is necessary to dephosphorylate and thus activate NF-AT, CsA prevents the activation of this transcription factor and thus the induced transcription of proinflammatory cytokines such as IL-2 (Matsuda et al., 2000). Aspirin (acetylsalicylic acid) which is one of the most widely used drugs worldwide, is a nonsteroidal anti-inflammatory drug (NSAIDs) that affects several pathways: First, it acetylates cyclooxygenases, thereby irreversibly blocking the conversion of arachidonic acid to prostanoids. Biotransformation of aspirin yields salicylate, a compound that possesses similar anti-inflammatory potency as aspirin but does not display aspirin's inhibitory effect on cyclooxygenase (Amann and Peskar, 2002). Second, very high concentrations of aspirin or salicylate also inhibit the activation of AP-1 or NF- $\kappa \mathrm{B}$ (Kopp and Medzhitov, 2002). The notion that commonly used anti-inflammatory agents frequently target proinflammatory signaling pathways shows that these pathways are ideally suited as drug targets.

\section{New drug targets: general considerations and a few examples}

During the last decade many key proteins and signaling networks mediating the inflammatory response have been discovered. It should be noted that the importance of these key enzymes often precludes their use as main drug targets, as exemplified by the inducible transcription factor $\mathrm{NF}-\kappa \mathrm{B}$. Long-lasting and systemic interference with the NF- $\kappa$ B system may cause severe side effects. The importance of a functioning NF- $\kappa$ B system is evident from mouse models where ablation of $\mathrm{p} 65$ or IKK $\beta$ leads to prenatal embryonic death (Ghosh, 2004). Interference with NF- $\kappa \mathrm{B}$ activation by selective deletion of IKK $\beta$ in enterocytes prevents the systemic inflammatory response, but also results in severe apoptotic damage to the reperfused intestinal mucosa (Chen et al., 2003). However, NF- $\kappa$ B inhibitors may still be of great therapeutical value when applied topical or for a limited period. Natural products have proved to be a rich source for the detection of NF- $\kappa$ B inhibitors including isoprenoid compounds, sesquiterpene lactones, triterpenoids and anti-oxidative phenolic compounds (Bremner and Heinrich, 2002).

Although available drugs alleviate many of the symptoms of disease, they often do not target the underlying causative mechanisms. In that respect, the NF- $\kappa \mathrm{B}$ transcription factor and the MAPK signaling pathways are at the apex of proinflammatory signaling. As NF- $\kappa \mathrm{B}$ is activated by cytokines such as IL- 1 and TNF $\alpha$ and these cytokines are among the numerous NF- $\kappa \mathrm{B}$ target genes, activation of this transcription factor allows the establishment of a signal amplification loop (Ghosh, 2004). This process is important during the early phase of infection and allows the rapid amplification of the inflammatory response. During inflammatory diseases, chronically hyperactivated NF- $\kappa \mathrm{B}$ and MAPK signaling can thus maintain inflammatory signaling even in the absence of pathogens (Tak and Firestein, 2001). Thus, drugs designed to break this vicious circle 
are promising for a causative therapy. As TNF $\alpha$ and IL-1 are crucial components driving this circle, their inactivation by the TNF neutralizing antibody infliximab (Remicade; Centocor) or the soluble IL-1 receptor antagonist Anakinra (Kineret; Amgen) are successfully used for the treatment of the inflammatory disease rheumatoid arthritis. Since the general inhibition of inflammatory signaling bears the potential danger to compromise the immune system or even general viability, new targets must be identified that are either operational in specific tissues or alternatively only affect a subset of target genes.

A prominent example for a cell type and pathway-specific member of the NF- $\kappa \mathrm{B}$ activation cascade is PKC $\theta$. This $\mathrm{Ca}^{2+}$-independent PKC isotype was isolated 10 years ago as a kinase selectively expressed in muscle cells and $\mathrm{T}$ lymphocytes (Baier et al., 1994). Biochemical and genetic approaches revealed that $\mathrm{PKC} \theta$ is required for the activation of mature T cells and IL-2 production, while it is dispensable for T-cell development. $\mathrm{PKC} \theta^{-/-} \mathrm{T}$ cells show impaired $\mathrm{T}$ cell receptor (TCR)-induced stimulation of the transcription factors AP-1 and NF- $\kappa$ B (Sun et al., 2000; Pfeifhofer et al., 2003). PKC $\theta$ integrates signals from the TCR and the costimulatory CD28 receptor, which are essential for productive T-cell activation and, most likely, for prevention of T-cell anergy. PKC $\theta$ also provides a survival signal, which protects $\mathrm{T}$ cells from apoptosis. PKC $\theta$ is selectively recruited to the central supramolecular activation complex region of the immunological synapse in antigen-stimulated $\mathrm{T}$ cells (Monks et al., 1998). This translocation is required for the activity of PKC $\theta$ and critically depends on the adaptor protein SLP-76, phospolipase $\mathrm{C} \gamma$ (Dienz et al., 2003) and further proteins including Vav1, phosphatidylinositol 3-kinase, the small GTPase Rac and reorganization of the actin cytoskeleton (Villalba et al., 2002). The selective expression and essential function of PKC $\theta$ in T-cell activation and survival suggest that pharmacological strategies designed to selectively block the function of this PKC isoform in $\mathrm{T}$ cells may be therapeutically useful. PKC $\theta$ inhibition could potentially abolish a T-cell survival signal and therefore promote the apoptosis of activated self-reactive $\mathrm{T}$ cells which play a role in several autoimmune diseases such as rheumatoid arthritis, insulin-dependent diabetes mellitus and multiple sclerosis.
Another interesting candidate controlling only a subset of NF- $\kappa \mathrm{B}$ target genes is $\mathrm{IKK} \varepsilon / \mathrm{IKKi}$. The IKK $\alpha / \beta$ homologue IKK $\varepsilon$ (Peters et al., 2000), also called IKKi (Shimada et al., 1999), has been implicated in NF- $\kappa$ B activation. Sequence comparison revealed that IKK $\varepsilon$ displays 33 and $31 \%$ amino acid identity with IKK $\alpha$ and IKK $\beta$, respectively, within the kinase domain,. The overall similarity throughout the entire sequence between the kinases is $27 \%$. Although recombinant IKK $\varepsilon$ directly phosphorylates only serine 36 of $\mathrm{I} \kappa \mathrm{B} \alpha$, the phorbol ester-activated endogenous IKK $\varepsilon$ complex phosphorylates both critical serine residues (Peters and Maniatis, 2001). Remarkably, this activity is due to the presence of a distinct so-far unknown kinase in this complex. A dominant-negative mutant of IKK $\varepsilon$ blocks induction of NF- $\kappa \mathrm{B}$ by both PMA and activation of the $\mathrm{T}$ cell receptor but has no effect on the activation of NF- $\kappa$ B by TNF $\alpha$ or IL-1. IKK $\varepsilon$ was revealed to be an essential component of the IRF3 signaling pathway (Fitzgerald et al., 2003), but there is also evidence for an involvement in the LPS response. Although the activation of the classical IKK complex is unchanged in $\mathrm{IKK} \varepsilon^{-/-}$cells, this kinase provides a link between signaling through the $\mathrm{NF}-\kappa \mathrm{B}$ and CCAAA/enhancer-binding protein $(\mathrm{C} / \mathrm{EBP})$ pathways. This link includes an NF- $\kappa \mathrm{B}$-dependent regulation of $\mathrm{C} / \mathrm{EBP} \beta$ and $\mathrm{C} / \mathrm{EBP} \delta$ gene transcription and IKK $\varepsilon$-mediated activation of C/EBP DNAbinding. Disruption of the NF- $\kappa \mathrm{B}$ pathway results in the blockade of the inducible up-regulation of $\mathrm{C} /$ $\operatorname{EBP} \beta, \mathrm{C} / \mathrm{EBP} \delta$, and $\mathrm{IKK} \varepsilon$ genes. Cells lacking $\mathrm{IKK} \varepsilon$ fail to induce $\mathrm{C} / \mathrm{EBP} \delta$ activity and transcription of $\mathrm{C} / \mathrm{EBP}$ and $\mathrm{C} / \mathrm{EBP}-\mathrm{NF}-\kappa \mathrm{B}$ target genes in response to LPS. IKK $\varepsilon$-deficient mice are perfectly viable and studies employing $\mathrm{IKK} \varepsilon^{-/-}$mouse embryonic fibroblasts reveal that this kinase is required for the induced expression of a number of NF- $\kappa$ B target genes including TNF, IL-1, IP-10, COX-2 and RANTES (Kravchenko et al., 2003). Other NF- $\kappa \mathrm{B}$ target genes including c-jun and many others remained completely unaffected, thus revealing that IKK $\varepsilon$ only controls a distinct subset of NF- $\kappa$ B-regulated genes. Given the role of IKK $\varepsilon$ for a defined array of genes and the non-essential role of this kinase for cell viability, this kinase is an attractive drug target.

Further interesting candidates come from recent findings elucidating non-classical, so-called non-canonical NF- $\kappa \mathrm{B}$ activation pathways that 
results in the release of p52/RelB (Senftleben et al., 2001a, b; Xiao et al., 2001)as well as p50/RelB dimers (Muller and Siebenlist, 2003). This pathway allows NIK- and IKK $\alpha$-dependent processing of the p100 protein, which results in the liberation of $\mathrm{p} 52$. The induction of $\mathrm{p} 100$ processing by overexpression of NIK does not occur in the absence of IKK $\alpha$, suggesting that NIK acts upstream from IKK $\alpha$ (Senftleben et al., 2001a, b). p100 processing is independent from the classical IKK complex and also occurs in the absence of IKK $\gamma /$ NEMO or IKK $\beta$ (Schiemann et al., 2001; Senftleben et al., 2001a, b). A physiologically relevant signal triggering p100 processing is lymphotoxin $\beta(\operatorname{LT} \beta)$, which is important for the organization and development of lymphoid tissues. Stimulation of the LT $\beta$ receptor induces NIK- and IKK $\alpha$-dependent p100 processing (Dejardin et al., 2002) and activation of the classical IKK complex. Accordingly, there are two subsets of LT $\beta$ R-induced genes, one activated by the canonical pathway and another set of genes activated by the non-canonical pathway (Dejardin et al., 2002). Therefore, inhibition of p100 processing would not affect all NF- $\kappa$ B-regulated genes and inhibitors interfering with this event are therefore of potential interest.

In addition to the NF- $\kappa \mathrm{B}$ system, also the MAPKs JNK and p38 are control switches for proinflammatory signaling, thus suggesting these kinases as 'drugable' structures. The JNK pathway is required for induced expression of TNF $\alpha$, IL-2, E-selectin, and MMPs such as collagenase-1 (Holzberg et al., 2003). MMPs promote cartilage and bone erosion in rheumatoid arthritis and generalized tissue destruction in other autoimmune diseases. Inducible expression of MMP3, MMP9 and collagenases is regulated by activation of the JNK pathway and AP-1 (Gum et al., 1997). Stimulation of human rheumatoid synoviocytes with TNF $\alpha$ or IL-1 activates the JNK pathway (Han et al., 1999). Activated JNK can also be detected in synovial fibroblasts and chondrocytes from the joints of osteoarthritic patients, but not from normal controls. Therefore JNK signaling has been suggested to play a role in chondrocyte injury and cartilage degeneration that are features of this disease (Clancy et al., 2001; Han et al., 2001). The dysregulation of JNK activity in multiple cell types involved in the inflammatory process has drawn attention to the development of JNK inhibitors as immuno-modulatory agents. The JNK inhibitor SP-600125 was reported as a selective inhibitor of JNKs 1,2 and $3\left(\mathrm{IC}_{50}=110-150 \mathrm{nM}\right)$, but with much less activity against the closely related p38 MAPK $\left(\mathrm{IC}_{50}>30 \mu \mathrm{M}\right)$. This inhibitor was tested in animal models of arthritis and asthma. SP-600125 inhibits IL-1-induced phosphorylation of JNK and c-Jun in synoviocytes from rheumatoid arthritis patients, and inhibits the production of MMP13 which is an important mediator of cartilage destruction (Han et al., 2001). Administration of SP-600125 also prevents JNK activation and collagenase expression in the joints of rats with adjuvant arthritis. Treated rats showed a significant reduction in paw swelling and reduced damage of bone and cartilage. These findings suggest that drugs targeting the JNK signaling pathway could be considered as a potential therapy for rheumatoid arthritis and also other inflammatory diseases.

The relevance of $\mathrm{p} 38$ for the inflammatory process is even evident from the history of its discovery, as it was identified as the molecular target of the pyridinyl imidazole class of compounds that were known to inhibit LPS-induced IL-1 and TNF production in human monocytes (Lee et al., 1994). A number of studies using the p38 inhibitor SB203580 revealed the contribution of $\mathrm{p} 38$ for induced expression of IL-1, TNF $\alpha$, COX2, MMPs, MCP-1, IL-6, IL-8 and NO synthases (Kracht and Saklatvala, 2002). The stimulatory effect of p38 relies on induced phosphorylation of transcription factors such as ATF2 but also on mRNA stabilization (Dean et al., 2003). Preclinical studies with p38 MAP kinase inhibitors indicate a crucial role of MAPK in inflammation. Specific and selective inhibitors block the production of proinflammatory cytokines and inflammatory mediators in vitro and in vivo. In addition, p38-dependent histone $\mathrm{H} 3$ phosphorylation marks and recruits NF- $\kappa \mathrm{B}$ to otherwise cryptic promoters, resulting in increased expression of several inflammatory cytokines and chemokines (Saccani et al., 2002). A large body of evidence from preclinical studies suggests a crucial role especially of the $\mathrm{p} 38$ isoform $\mathrm{p} 38 \alpha$ in inflammation.

Blocking of p38 activity has been shown to be effective in animal models of rheumatoid arthritis, which is characterized by a debilitating joint destruction that can be attributed to ongoing chronic inflammation of the synovial lining. 
Infiltration of this tissue with immunocompetent cells and proliferation of synovial fibroblasts leads to the formation of pannus tissue, which invades and destroys the subchondral bone and articular cartilage. As rheumatoid arthritis is characterized by constitutively high levels of TNF $\alpha$, IL-1, IL-6, IL-7 and IL-12, interference with the production of these cytokines by the p38 inhibitor FR167653 prevents the onset and progression of collageninduced arthritis in rats (Nishikawa et al., 2003). Several novel imidazole analogues based on the structures of the original p38 MAPK inhibitors have now entered clinical studies and it will be interesting to see their efficacy.

\section{Concluding remarks}

Here we concentrated on featuring protein kinases as molecular targets for anti-inflammatory agents. The reason is, that most of the available preclinical and clinical data were obtained from this class of enzymes. On the other hand, proteins with other enzymatic activities including phosphatases, phospholipases and many others deserve a closer look for their suitability as drug targets. Since signal transduction networks are highly connected and mutually regulated, it might be advantageous to inhibit more than one target. Thus, the above mentioned commonly used anti-inflammatory drugs aspirin and glucocorticoids affect more than a single molecule and it is tempting to speculate that exactly this attribute allows their potent efficacy. The complex nature of phytochemical preparations often allows the simultaneous inhibition of several pathways, making these extracts ideally suited and used for treatment of inflammatory diseases. There remains still a lot to be learned on the target proteins in order to combine maximal efficacy with minimal side effects.

\section{Acknowledgements}

We apologize to all scientists who made important discoveries to the issue discussed here and could not be cited due to the limitation of space. We are grateful for the support of our work by the EU FP6 program, Oncosuisse, Swiss National Science Foundation and Association for International Cancer Research.

\section{References}

Alsayed Y, Uddin S, Mahmud N, Lekmine F, Kalvakolanu DV, Minucci S, Bokoch G \& Platanias LC (2001) Activation of Racl and the p38 mitogen-activated protein kinase pathway in response to all-trans-retinoic acid. J. Biol. Chem. 276: 4012-4019.

Amann R \& Peskar BA (2002) Anti-inflammatory effects of aspirin and sodium salicylate. Eur. J. Pharmacol. 447: 1-9.

Baier G, Baier-Bitterlich G, Meller N, Coggeshall KM, Giampa L, Telford D, Isakov N \& Altman A (1994) Expression and biochemical characterization of human protein kinase C-theta. Eur. J. Biochem. 225: 195-203.

Bremner P. \& Heinrich M. (2002) Natural products as targeted modulators of the NF-kappaB pathway. J. Pharm. Pharmacol. 54: 453-472.

Caelles C, Gonzalez-Sancho JM \& Munoz A (1997) Nuclear hormone receptor antagonism with AP-1 by inhibition of the JNK pathway. Genes Dev. 11: 3351-3364.

Chen G \& Goeddel DV (2002) TNF-R1 signaling: a beautiful pathway. Science 296: 1634-1635.

Chen LW, Egan L, Li ZW, Greten FR, Kagnoff MF \& Karin M (2003) The two faces of IKK and NF-kappaB inhibition: prevention of systemic inflammation but increased local injury following intestinal ischemia-reperfusion. Nat. Med. 9: $575-581$.

Clancy R, Rediske J, Koehne C, Stoyanovsky D, Amin A, Attur M, Iyama K \& Abramson SB (2001) Activation of stress-activated protein kinase in osteoarthritic cartilage: evidence for nitric oxide dependence. Osteoarthr. Cartilage 9: 294-299.

De Bosscher K, Vanden Berghe W \& Haegeman G (2003) The interplay between the glucocorticoid receptor and nuclear factor-kappaB or activator protein-1: molecular mechanisms for gene repression. Endocr. Rev. 24: 488-522.

Dean JL, Sarsfield SJ, Tsounakou E \& Saklatvala J (2003) p38 Mitogen-activated protein kinase stabilizes mRNAs that contain cyclooxygenase-2 and tumor necrosis factor AU-rich elements by inhibiting deadenylation. J. Biol. Chem. 278: 39470-39476.

Dejardin E, Droin NM, Delhase M, Haas E, Cao Y, Makris C, Li ZW, Karin M, Ware CF \& Green DR (2002) The lymphotoxin-beta receptor induces different patterns of gene expression via two NF-kappaB pathways. Immunity 17: 525-535.

Dienz O, Moller A, Strecker A, Stephan N, Krammer PH, Droge W \& Schmitz ML (2003) Src homology 2 domaincontaining leukocyte phosphoprotein of $76 \mathrm{kDa}$ and phospholipase $\mathrm{C}$ gamma 1 are required for NF-kappa B activation and lipid raft recruitment of protein kinase $\mathrm{C}$ theta induced by T cell costimulation. J. Immunol. 170: 365-372.

Dong C, Davis RJ \& Flavell RA (2002) MAP kinases in the immune response. Annu. Rev. Immunol. 20: 55-72.

Dunne A \& O'Neill LA (2003) The interleukin-1 receptor/Tolllike receptor superfamily: signal transduction during inflammation and host defense. Sci. STKE 2003: re3.

Fitzgerald KA, McWhirter SM, Faia KL, Rowe DC, Latz E, Golenbock DT, Coyle AJ, Liao SM \& Maniatis T (2003) IKKepsilon and TBK 1 are essential components of the IRF3 signaling pathway. Nat. Immunol. 4: 491-496.

Ghosh S (2004) Signaling to NF-kappaB Genes Dev. 18: 2195 2224.

Gum R, Wang H, Lengyel E, Juarez J \& Boyd D (1997) Regulation of $92 \mathrm{kDa}$ type IV collagenase expression by 
the jun aminoterminal kinase- and the extracellular signalregulated kinase-dependent signaling cascades. Oncogene 14: 1481-1493.

Han Z, Boyle DL, Aupperle KR, Bennett B, Manning AM \& Firestein GS (1999) Jun N-terminal kinase in rheumatoid arthritis. J. Pharmacol. Exp. Ther. 291: 124-130.

Han Z, Boyle DL, Chang L, Bennett B, Karin M, Yang L, Manning AM \& Firestein GS (2001) c-Jun N-terminal kinase is required for metalloproteinase expression and joint destruction in inflammatory arthritis. J. Clin. Invest. 108: 73-81.

Holzberg D, Knight CG, Dittrich-Breiholz O, Schneider H, Dorrie A, Hoffmann E, Resch K \& Kracht M (2003) Disruption of the c-JUN-JNK complex by a cell-permeable peptide containing the c-JUN delta domain induces apoptosis and affects a distinct set of interleukin-1-induced inflammatory genes. J. Biol. Chem. 278: 40213-40223.

Ishizuka T, Kawasome H, Terada N, Takeda K, Gerwins P, Keller GM, Johnson GL \& Gelfand EW (1998) Stem cell factor augments Fc epsilon RI-mediated TNF-alpha production and stimulates MAP kinases via a different pathway in MC/9 mast cells. J. Immunol. 161: 3624-3630.

Johnson GL \& Lapadat R (2002) Mitogen-activated protein kinase pathways mediated by ERK, JNK, and p38 protein kinases. Science 298: 1911-1912.

Johnston B \& Butcher EC (2002) Chemokines in rapid leukocyte adhesion triggering and migration. Semin. Immunol. 14: 83-92.

Kopp E \& Medzhitov R (2002) Skin antibiotics get in the loop. Nat. Med. 8: 1359-1360.

Kracht M \& Saklatvala J (2002) Transcriptional and posttranscriptional control of gene expression in inflammation. Cytokine 20: 91-106.

Kravchenko VV, Mathison JC, Schwamborn K, Mercurio F \& Ulevitch RJ (2003) IKKi/IKKepsilon plays a key role in integrating signals induced by pro-inflammatory stimuli. J. Biol. Chem. 278: 26612-26619.

Kubo M, Hanada T \& Yoshimura A (2003) Suppressors of cytokine signaling and immunity. Nat. Immunol. 4: 1169-1176.

Kumar S, Blake SM \& Emery JG (2001) Intracellular signaling pathways as a target for the treatment of rheumatoid arthritis. Curr. Opin. Pharmacol. 1: 307-313.

Kumar S, Boehm J \& Lee JC (2003) p38 MAP kinases: key signalling molecules as therapeutic targets for inflammatory diseases. Nat. Rev. Drug Discov. 2: 717-726.

Lee JC, Laydon JT, McDonnell PC, Gallagher TF, Kumar S, Green D, McNulty D, Blumenthal MJ, Heys JR, Landvatter SW \& . (1994) A protein kinase involved in the regulation of inflammatory cytokine biosynthesis Nature 372: 739-746.

Manning AM \& Davis RJ (2003) Targeting JNK for therapeutic benefit: from junk to gold?. Nat. Rev. Drug Discov. 2: 554-565.

Marra F (2002) Chemokines in liver inflammation and fibrosis Front. Biosci. 7: d1899-d1914.

Matsuda S, Shibasaki F, Takehana K, Mori H, Nishida E \& Koyasu S (2000) Two distinct action mechanisms of immunophilin-ligand complexes for the blockade of T-cell activation. EMBO Rep. 1: 428-434.

Monks CR, Freiberg BA, Kupfer H, Sciaky N \& Kupfer A (1998) Three-dimensional segregation of supramolecular activation clusters in T cells. Nature 395: 82-86.

Muller JR \& Siebenlist U (2003) Lymphotoxin beta receptor induces sequential activation of distinct NF-kappa B factors via separate signaling pathways. J. Biol. Chem. 278: 1200612012.
Nishikawa M, Myoui A, Tomita T, Takahi K, Nampei A \& Yoshikawa H (2003) Prevention of the onset and progression of collagen-induced arthritis in rats by the potent p38 mitogen-activated protein kinase inhibitor FR167653. Arthritis Rheum. 48: 2670-2681.

Pedersen IM, Buhl AM, Klausen P, Geisler CH \& Jurlander J (2002) The chimeric anti-CD20 antibody rituximab induces apoptosis in B-cell chronic lymphocytic leukemia cells through a p38 mitogen activated protein-kinase-dependent mechanism. Blood 99: 1314-1319.

Peters RT, Liao SM \& Maniatis T (2000) IKKepsilon is part of a novel PMA-inducible IkappaB kinase complex. Mol. Cell 5: 513-522.

Peters RT \& Maniatis T (2001) A new family of IKK-related kinases may function as I kappa B kinase kinases. Biochim. Biophys. Acta 1471: M57-M62.

Pfeifhofer C, Kofler K, Gruber T, Tabrizi NG, Lutz C, Maly K, Leitges M \& Baier G (2003) Protein kinase C theta affects $\mathrm{Ca}^{2+}$ mobilization and NFAT cell activation in primary mouse T cells. J. Exp. Med. 197: 1525-1535.

Saccani S, Pantano S \& Natoli G (2002) p38-Dependent marking of inflammatory genes for increased NF-kappa B recruitment. Nat. Immunol. 3: 69-75.

Schiemann B, Gommerman JL, Vora K, Cachero TG, ShulgaMorskaya S, Dobles M, Frew E \& Scott ML (2001) An essential role for BAFF in the normal development of B cells through a BCMA-independent pathway. Science 293: 2111-2114.

Senftleben U, Cao Y, Xiao G, Greten FR, Krahn G, Bonizzi G, Chen Y, Hu Y, Fong A, Sun SC \& Karin M (2001a) Activation by IKKalpha of a second, evolutionary conserved, NF-kappaB signaling pathway. Science 293: 1495-1499.

Senftleben U, Cao Y, Xiao G, Greten FR, Krahn G, Bonizzi G, Chen Y, Hu Y, Fong A, Sun SC \& Karin M (2001b) Activation by IKKalpha of a second, evolutionary conserved, NF-kappaB signaling pathway. Science 293: 1495-1499.

Shimada T, Kawai T, Takeda K, Matsumoto M, Inoue J, Tatsumi Y, Kanamaru A \& Akira S (1999) IKK-i, a novel lipopolysaccharide-inducible kinase that is related to IkappaB kinases. Int. Immunol. 11: 1357-1362.

Sun Z, Arendt CW, Ellmeier W, Schaeffer EM, Sunshine MJ, Gandhi L, Annes J, Petrzilka D, Kupfer A, Schwartzberg PL \& Littman DR (2000) PKC-theta is required for TCRinduced NF-kappaB activation in mature but not immature T lymphocytes. Nature 404: 402-407.

Tak PP \& Firestein GS (2001) NF-kappaB: a key role in inflammatory diseases. J. Clin. Invest. 107: 7-11.

Ventura JJ, Kennedy NJ, Lamb JA, Flavell RA \& Davis RJ (2003) c-Jun NH(2)-terminal kinase is essential for the regulation of AP-1 by tumor necrosis factor. Mol. Cell. Biol. 23: 2871-2882.

Villalba M, Bi K, Hu J, Altman Y, Bushway P, Reits E, Neefjes J, Baier G, Abraham RT \& Altman A (2002) Translocation of PKC[theta] in T cells is mediated by a nonconventional, PI3-K- and Vav-dependent pathway, but does not absolutely require phospholipase C. J. Cell Biol. 157: 253-263.

Winrow VR, Winyard PG, Morris CJ \& Blake DR (1993) Free radicals in inflammation: second messengers and mediators of tissue destruction. Br. Med. Bull. 49: 506-522.

Xiao G, Harhaj EW \& Sun SC (2001) NF-kappaB-inducing kinase regulates the processing of NF-kappaB2 p100. Mol. Cell 7: 401-409. 